\title{
Role of Multi-Pamatric MRI in Loco-Regional Staging of Prostatic Cancer
}

\author{
HALA M. AHMED, M.D.*; AHMED E. EBEED, M.D.*; AHMED H. MHSB, M.Sc.*; \\ AHMED A. ABDEL RAZEK, M.D.** and MOHAMED ABOU EL-GHAR, M.D.*** \\ The Department of Diagnostic Radiology, Faculty of Medicine, Aswan*, Mansoura** Universities and \\ Mansoura Urology \& Nephrology Center, Mansoura***, Egypt
}

\begin{abstract}
Background: Prostate cancer is a worldwide common neoplastic disease in males. Loco-regional Staging of pathologically proved Prostate cancer is of great impact on management planning. Multi-parametric MRI is a novel highly sensitive modality in the evaluation of local behavior and aggressiveness of prostatic tumors.

Aim of Study: This study aimed to assess the ability of Mult-Parmateric MRI in assessing the loco-regional features and aggressiveness of the proved prostatic cancer and how that will impact the therapeutic individual planes.

Methods: We evaluated 40 male patients (mean age 69 years, range 56-87 years) with pathologically proved prostate cancer. They underwent a Multi-parametric MRI examination at (1.5T Toshiba - USA) at Aswan University Hospital after at least 6 weeks after TRUS biopsy. MRI protocol included T2WI, diffusion-weighted MR and Dynamic Contrast (DCE). Each examination was analyzed to asses the diagnostic performance of multi-parametric MRI in the assessment of extra-capsular extension, seminal vesicles, and neurovascular bundle infiltration as well as regional lymphadenopathy with the histopathologic data from radical prostatectomy as the gold-standard reference.
\end{abstract}

Results: Twenty patients (50\%) out of 40 patients proved to have extra-capsular extension, 15 patients $(37.5 \%)$ proved to have NVB infiltration, and 10 patients $(20 \%)$ proved to have seminal vesicles invasion. Pelvic LNs were detected in 30 patients $(75 \%)$. mpMRI in the loco-regional assessment of prostatic cancer showed high sensitivity and specificity.

Conclusion: MRI is a non-invasive technique that provided a highly sensitive method in loco-regional evaluation and staging of the proved prostate cancer giving excellent impression regarding the aggressiveness of the tumor, leading to better and cost-effective management and save unnecessary invasive procedure.

Key Words: Diffusion-Prostate - Cancer-Prognosis Magnetic resonance imaging.

Correspondence to: Dr. Hala M. Ahmed, The Department of Diagnostic Radiology, Faculty of Medicine, Aswan University

\section{Introduction}

PROSTATIC cancer recently considered as the 2nd most common reason for cancer affecting men in the USA, and it causes about $8 \%$ of cancer related deaths [1-3].

Evaluation of the Loco-regional aggressiveness factors is essential for the treatment strategy and prognosis of patients with prostate malignancy [4].

Owing to the tremendous upgrades in the of MRI machines giving perfectly detailed anatomical and functional features of the prostate gland as well as the pathologic features of the prostate cancers with high resolution and soft-tissue characterization, and with no risk of radiation or hazard of renal injury [5].

Multi-Parmatreic MRI is currently believed to be one of the most valuable non-invasive excellent technique in assessing and featuring the prostatic lesions. Features such extra-prostatic extension and regional lymphadenopathy are cornerstone points in planning individual regimen and procedures needed for every patient [6].

This study aimed to assess the ability of MultParmateric MRI in assessing the loco-regional features and aggressiveness of the proved prostatic cancer and how that will impact the therapeutic individual planes.

\section{Patients and Methods}

\section{Patient population:}

Approval from the local Ethics Committee was obtained for this study and all patients gave written informed consent before the commencement of MR imaging. Patients had pathologically proved prostate cancer During January 2018 and August 
2019, prospective study was carried out on 40 patients. All patients referred from the urology out-clinics at Aswan University Hospital. Five patients were excluded from this study had claustrophobic and 1 with cardiac pacemakers.

\section{MR imaging technique:}

All MRI studies were performed at (1.5T Toshiba - USA). The patient examined in the supine position using a phased-array 16-multi-channel pelvic phased-array surface coil. The protocol followed the PIRADS that included routine $\mathrm{T} 1$ weighted images, multi-planar high-resolution T2 weighted images in the axial, sagittal and coronal planes, with a section thickness $=5 \mathrm{~mm}$ with Diffusion-weighted images (DWI) were obtained through the whole prostate gland at high $b$ values ( 800-1000-1200). DCE was obtained using.

\section{Image analysis:}

Image analysis was done by an expert radiologist (SF). The Radiologist examined T2WI, and DWI, DCE then conclude the lesion criteria including the extra-capsular extension, NVB, seminal vesicles invasion, and regional Lymphadenopathy.

\section{Histopathological examination:}

Patients underwent radical prostatectomy. An expert pathologist examined the prostate specimen and report it.

\section{Statistical analysis:}

Data entry was done by SPSS last version and analyzed by the same software. The sensitivity, specificity and overall accuracy were calculated in comparison with the gold standard (histopathology of the biopsied cores). The probability ( $p$ value) of less than 0.05 was used as a cutoff point for all significant tests.

\section{Results}

This prospective study included 40 males, and their ages ranged from 55 to 87 years (mean age was 65 years). The majority of prostate cancers index lesions involved the peripheral zone as it was encountered in 29 out of 40 patients, while 10 cancers at the $\mathrm{TZ}$ and 1 case at the central zone ( Table 1). Prostatic cancer was graded and classified based on the Gleason score (Table 2).

Pathologically proved cancer, underwent $\mathrm{Mp}$ MRI scans. Histopathology examination was considered the gold standard for our study, classifying the cases depending on the loco-regional behavior and aggressiveness. Twenty patients $(50 \%)$ out of 40 patients proved to have extra-capsular extension,
15 patients $(37.5 \%)$ proved to have NVB infiltration, and 10 patients $(20 \%)$ proved to have seminal vesicles invasion. Pelvic LNs were detected in 30 patients $(75 \%)$.

The diagnostic performance of mp-MRI in detecting extra-prostatic extension (EXC) of index prostatic lesions showed high sensitivity and specificity especially when the lesion found in the PZ. Sensitivity and specificity was $(78 \%$ and $80 \%)$ respectively.

Regarding Neuro-vascular bundle (NVB) invasion, mp-MRI showed excellent sensitivity especially when helped by the DCE, with sensitivity ( 83\%) and specificity (79\%).

Seminal vesicles (SV) infiltration detected and compared to the prostatectomy specimen showed high sensitivity and relatively lower specificity as many false negative due to chronic SV inflammation, with sensitivity (79\%) and specificity (63\%).

Regional lymphadenopathy detected by the wide-field T2WI and confirmed by restricted DWI and a low signal at ADC and contrast uptake and DCE. Sensitivity and specificity was $(90 \%$ and $82 \%$ ) respectively (Table 3 ).

Table (1): PSA value and ratio for the studied.

\begin{tabular}{cll}
\hline No. of cases $(\mathrm{n}=40)$ & \multicolumn{1}{c}{ Site } & Percentage $(\%)$ \\
\hline 29 & Peripheral zone & 72.5 \\
10 & Transitional zone & 25 \\
1 & Central zone & 2.5 \\
\hline
\end{tabular}

Table (2): Gleason score for the study group (prostate cancer) No. of cases $(n=40)$.

\begin{tabular}{clc}
\hline Gleason Score & No & Percentage (\%) \\
\hline $4+3$ & 4 & 10 \\
$4+4$ & 6 & 15 \\
$4+5$ & 10 & 25 \\
$5+4$ & 9 & 22.5 \\
$5+4$ & 11 & 27.5 \\
\hline
\end{tabular}

Table (3): Sensitivity and specificity of mpMRI in the prostatic cancer loco-regional evaluation.

\begin{tabular}{lcccccc}
\hline Parameter & $\begin{array}{c}\text { Sensi- } \\
\text { tivity }\end{array}$ & ficity & & & PPV NPV & uracy value \\
\hline ECE & $78 \%$ & $80 \%$ & $77 \%$ & $68 \%$ & $79 \%$ & 0.087 \\
NVB infiltration & $83 \%$ & $79 \%$ & $86 \%$ & $70 \%$ & $78 \%$ & 0.087 \\
SV invasion & $79 \%$ & $63 \%$ & $68 \%$ & $59 \%$ & $69 \%$ & 0.087 \\
Regional LNs & $90 \%$ & $82 \%$ & $88 \%$ & $83 \%$ & $87 \%$ & 0.001 \\
\hline
\end{tabular}



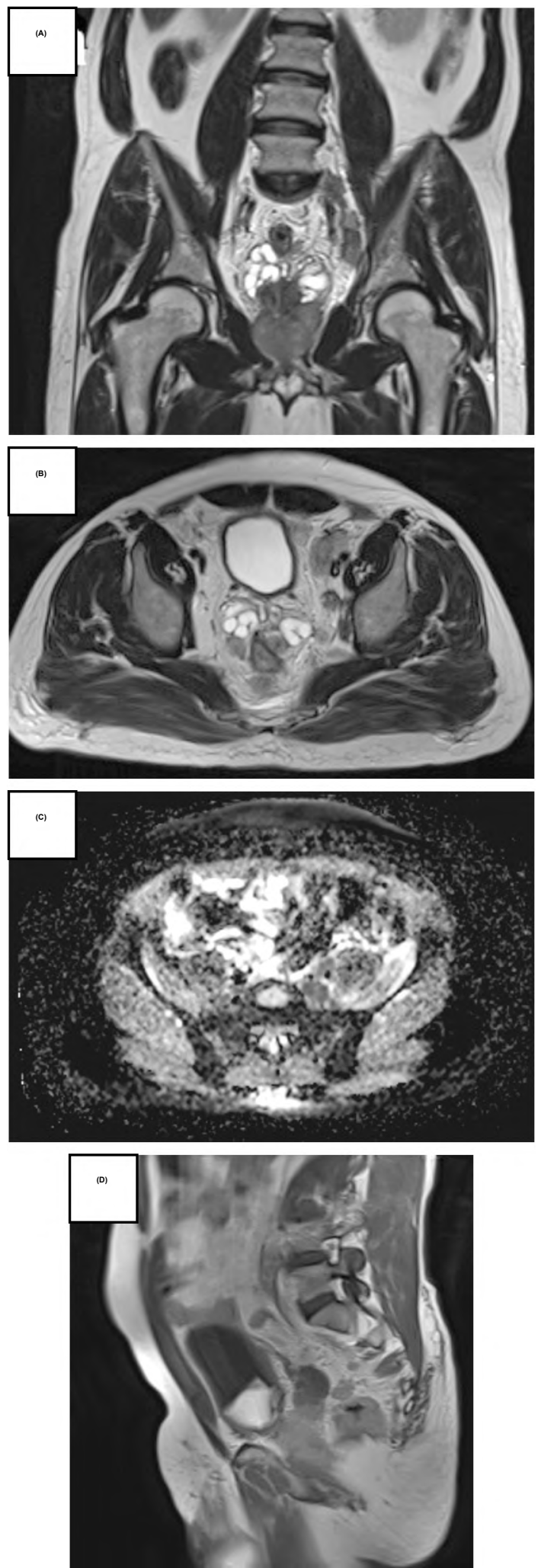

Fig. (1): (A,B) T2WI high resolution coronal \& axial images show multiple enlarged LNs, largest seen at the left iliac group as well as an abnormal signal of both seminal vesicles. (C) ADC axial image shows markedly hypointense signal of the enlarged LNs. (D) T $1 \mathrm{WI}+\mathrm{C}$ Show heterogeneous enhancement of the enlarged LNs.

Histopathologically approved Prostatic cancer $(\mathrm{GS}=5+4)$ and confirmed the presence of nodal deposits and $\mathrm{SV}$ invasion.

\section{Discussion}

This study aimed to evaluate the ability and accuracy of the MP-MRI in characterization and assessment of the loco-regional behavior and aggressiveness of the proved prostatic cancers. The study was conducted on 40 patients. The majority of the studied cases were above 50 years.

The recent planes for treating prostatic cancers may have over or under valuating the disease with consequent irrelevant management [2-6]. That is why our study is concerned about the detailed and better characterization of loco-regional features and grade of aggressiveness of the proved cancers using Mp-MRI in the pretreatment assessment of prostate cancer.

Nodal metastases of prostate cancer are seen in $10-15 \%$ of patients at presentation. The rank and features of the detected local lymph nodes found to affect the patient treatment plan and allover prognosis [7].

Previous studies reported that the ADC value correlates with $\mathrm{T}$ staging of head and neck cancer, salivary cancer and urinary bladder cancer [8]. One study reported that ADC has superior diagnostic performance than routine pre and post-contrast MR imaging in forecasting muscle infiltration of patients with urinary bladder cancer [9]. Other studies added that greater $\mathrm{T}$ stages of salivary gland cancerous lesions have lower ADC value (10) and there is a significant variance in the ADC value between different sizes of retinoblastoma $(p=0.015)$

In the current study, the cancerous $\mathrm{ADC}$ value seen with $\mathrm{N} 1$ is lower regarding to ADC values with NO. The explanation might be related to that cancer with an advanced $\mathrm{N}$ stage is commonly seen in the higher grade of malignancy. Nodal metastases of prostate cancer are seen in $10-15 \%$ of patients at presentation. The rank and features of the detected local lymph nodes found to have an effect on the patient treatment plan and allover prognosis

[12]. One study concluded that ADC value was significantly lower $(p=0.003)$ in a patient with nasopharyngeal carcinoma in the case of positive metastatic cervical lymph nodes [13].

In our work, the ADC of cancer M0 stage is significantly different $(p=0.001)$ from patients with M 1 stage cancer prostate. The recognition of distant secondaries at the earliest diagnosis of prostate cancer establishes the treatment methodology and has a great prognostic value. The application of whole-body DWI helps in the detection of distant 
metastasis of prostate cancer [14]. Metastasis Reporting and Data System for Prostate Cancer is a scoring system that recently applied in clinical practice [14].

\section{Conclusion:}

MRI is a non-invasive technique that provided a highly sensitive method in loco-regional evaluation and staging of the proved prostate cancer giving excellent impression regarding the aggressiveness of the tumor, leading to better and costeffective management and save unnecessary invasive procedure.

\section{Conflict of interest:}

The authors state that there is no conflict of interest.

\section{References}

1- LEE H., LEE M., BYUN S.S., LEE S.E. and HONG S.K. Evaluation of Prostate Cancer Stage Groups Updated in the 8th Edition of the American Joint Committee on Cancer Tumor-Node-Metastasis Staging Manual. Clin. Genitourin Cancer, 17: e221-6, 2019.

2- PANER G.P., GANDHI J., CHOY B. and AMIN M.B.: Essential Updates in Grading, Morphotyping, Reporting, and Staging of Prostate Carcinoma for General Surgical Pathologists. Arch. Pathol. Lab. Med., doi: 10.5858/ arpa.2018-0334-RA, 2019.

3- VARMA M., COCHLIN D., DELAHUNT B., KYNASTON H., REES J., ROUS B., et al.: TNM c linical staging of prostate cancer: Issues and solutions. BJU Int. , 123:382-384, 2019.

4- BRAUNHUT B.L., PUNNEN S. and KRYVENKO O.N.: Updates on Grading and Staging of Prostate Cancer. Surg. Pathol. Clin., 11: 759-74, 2018.

5- KUNDRA V., SILVERMAN P.M., MATIN S.F. and CHOI H.: Imaging in oncology from the University of Texas
MD Anderson Cancer Center: Diagnosis, staging, and surveillance of prostate cancer. Am. J. Roentgenol., 189 (4): 830, 2007.

6- DESOUZA N.M., REINSBERG S.A., SCURR E.D., BREWSTER J.M. and PAYNE G.S.: Magnetic resonance imaging in prostate cancer: The value of apparent diffusion coefficients for identifying malignant nodules. The British Jounralof Radiology, Feb., 80 (950): 90-5, 2007.

7- CAGLIC I. and BARRETT T.: Diffusion-weighted imaging ( DWI) in lymph node staging for prostate cancer. Transl. Androl. Urol., 7: 814-23, 2018.

8- ABDEL RAZEK A.A.K., ELKHAMARY S.M. and NADA N.: Correlation of apparent diffusion coefficient with histopathological parameters of salivary gland cancer. Int. J. Oral Maxillofac. Surg., doi: 10.1016/j.ijom.2019. 03.897, 2019.

9- RAZIK A., DAS C.J., SHARMA S., SETH A., SRIVASTAVA D.N., MATHUR S., et al.: Diagnostic performance of diffusion-weighted MR imaging at 3.0 T in predicting muscle invasion in urinary bladder cancer: Utility of evaluating the morphology of the reactive tumor stalk. Abdom. Radiol., 43: 2431-41, 2018.

10- ABDEL RAZEK A.A., ELKHAMARY S., AL-MESFER S. and ALKATAN H.M.: Correlation ofapparent diffusion coefficient at $3 \mathrm{~T}$ with prognostic parameters of retinoblastoma. Am. J. Neuroradiol., 33: 944-8, 2012.

11- CAGLIC I. and BARRETT T.: Diffusion-weighted imaging ( DWI) in lymph node staging for prostate cancer. Transl. Androl. Urol., 7: 814-23, 2018.

12- ABDEL RAZEK A.A. and KAMAL E.: Nasopharyngeal carcinoma: correlation of apparent diffusion coefficient value with prognostic parameters. Radiol. Med., 118: 534-9, 2013.

13- PESAPANE F., CZARNIECKI M., SUTER M.B., TURKBEY B. and VILLEIRS G.: Imaging of distant metastases of prostate cancer. Med. Oncol., 35: 148, 2018.

14- PADHANI A.R., TUNARIU N.: Metastasis Reporting and Data System for Prostate Cancer in Practice. Magn Reson Imaging Clin. North Am., 26: 527-42, 2018. 


\section{دور الرنين المغناطيسى متعدد الطرائق

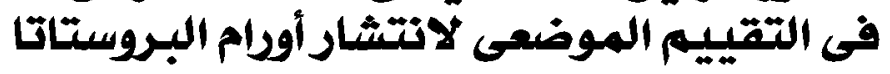

سرطان البروستاتا من الأودام الأكثر شيوعاً بين الذكود فى مختف البلدان المتقدمة والنامية على السواء وتختلف طرق العلاج والجراحات المستخدمة تبعاً لطبيعة انتشار الورم وحدته.

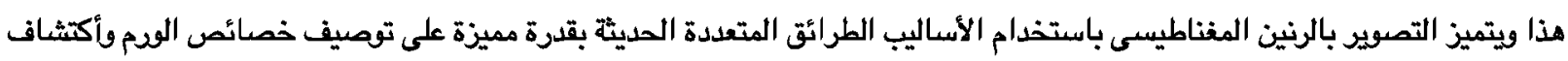
إمتداده خارج البروستاتا وكذلك انتشاره بالغدد اليمفاوية المحيطة.

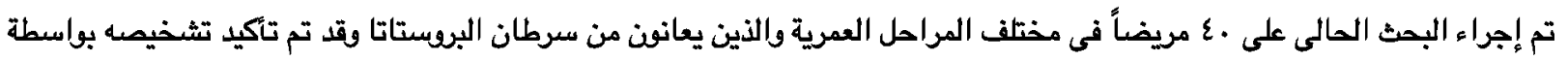

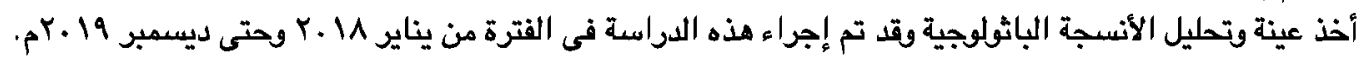

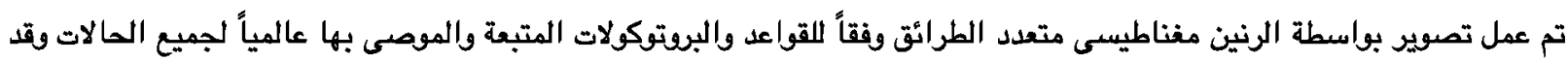

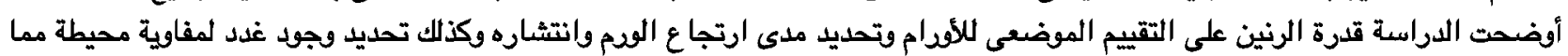

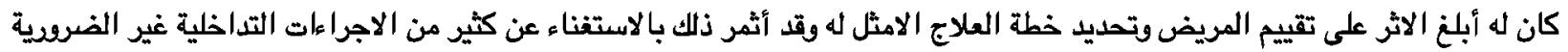

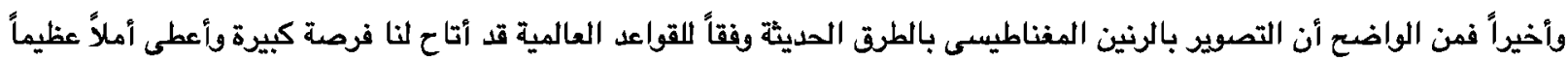

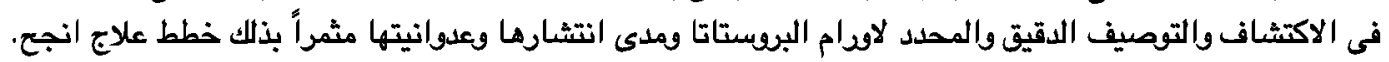
وخلص البحث إلى إن التصوير بالرنين المفناطيسى متعدد الطرائق هو أداة تشخيص دقيقة ومتطورة وآمنة لتقييم أورام البروستاتا وينبغى التئ

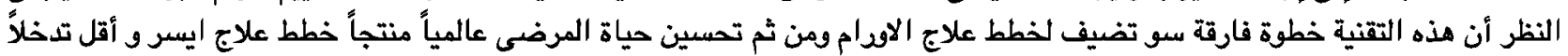
وتكلفة وكذلك أعلى نجاحاً. 